Boston University School of Law

Scholarly Commons at Boston University School of Law

Faculty Scholarship

1998

A National Bill of Patients' Rights

George J. Annas

Follow this and additional works at: https://scholarship.law.bu.edu/faculty_scholarship

Part of the Health Law and Policy Commons 
Legal Issues in Medicine

\section{A National Bill of Patients' Rights}

\author{
George J. AnnAS, J.D., M.P.H.
}

I $\mathrm{N}$ one of the most enthusiastically received proposals in his January State of the Union address, President Bill Clinton called on Congress to enact a national bill of rights in health care. The President said, "You have the right to know all your medical options, not just the cheapest. You have the right to choose the doctor you want for the care you need. You have the right to emergency room care, wherever and whenever you need it. You have the right to keep your medical records confidential."1

The President's proposal is a follow-up to his November 1997 announcement that he would put the recommendations of his Advisory Commission on Consumer Protection and Quality in the Health Care Industry into federal law. This in turn follows proposals from almost every state legislature, the American Association of Health Plans (AAHP), and an ad hoc group of nonprofit health maintenance organizations to provide Americans enrolled in health plans with new protections. The last time patients' rights were at the center of national debate was in the early 1970s. In this article I summarize the short history of patients' rights in the United States and the attempt to transform patients' rights into consumers' rights, and I explain how a synthesis of patients' rights and consumers' rights, enacted in federal legislation, could move us toward a more responsive and responsible health care system.

\section{PATIENTS' RIGHTS IN THE 1970s}

As Starr has chronicled, in the early 1970s, the movement to establish a right to health care was joined (some would say eclipsed) by a movement to establish rights in health care. ${ }^{2}$ The right to health care demanded federal legislation and financing, but rights in health care were almost always enunciated by the courts. ${ }^{3}$

The most important of all patients' rights, the right to informed consent, was firmly established in 1972 in a series of court opinions. ${ }^{3}$ In these opinions the courts made it clear that the law would treat the doctor-patient relationship as a fiduciary, or trust-based relationship, not as an arm's-length business relationship. The nature of this relationship is that a sick person (a patient) seeks the help of a specially educated and experienced professional, who is licensed by the state to practice medicine and whose unequal status vis-à-vis the patient requires the physician to assume certain legal responsibilities for the patient. These responsibilities are inherent in the doctor-patient relationship and require that before obtaining the patient's consent to treatment, the physician provide the patient with basic information so that the patient (not the physician) can make the final decision about whether to proceed. This information includes a description of the proposed treatment, its anticipated risks and benefits, alternative treatments (including none) and their risks and benefits, the probability of success, and the chief anticipated problems of recuperation. ${ }^{3,4}$

All this seems fairly standard 25 years later, but it was radical at the time. Before the 1970s, informed consent was not promoted or embraced by physicians and had to be imposed on them by the courts. Nonetheless, the concept of informed consent quickly became an ethical precept and has served both patients and their physicians well. ${ }^{5}$

The requirement of informed consent was followed quickly by other requirements intended to enhance the autonomy of patients. Autonomy or liberty (sometimes reduced simply to the idea of choice) is, of course, the fundamental American value, and it is somewhat remarkable that medicine had been insulated from it until the 1970s. It is not surprising, then, that patients' rights based on autonomy quickly became the norm. In early 1973, for example, the U.S. Supreme Court issued what is still its most important medicine-related opinion, in Roe v. Wade. ${ }^{6}$ The Court held that pregnant women have a constitutional right of privacy that includes their right to continue or terminate a pregnancy in the absence of the state's ability to demonstrate a countervailing and compelling state interest. The case has also come to stand for the proposition that the Constitution limits interference by the state in the doctor-patient relationship. ${ }^{7}$

Also in early 1973, the American Hospital Association issued a patients' bill of rights. ${ }^{3}$ Although the 12 -point bill was vague and general, it was the first such document and included many basic concepts of patients' rights, such as the rights to receive respectful care, to be given complete information about diagnosis and prognosis, to refuse treatment, to refuse to participate in experiments, to have privacy and confidentiality maintained, and to receive a reasonable response to a request for services. ${ }^{3}$

In an era when the use of medical technology was sometimes considered more important than its effectiveness in meeting patients' needs, the courts were again called on to enhance the power of patients. For example, in a series of cases, beginning in 1976 with the case of Karen Ann Quinlan and culminating in 1997 with cases concerning physicianassisted suicide, the courts affirmed that competent patients have the right to refuse any medical treat- 
ment, including life-sustaining treatment. ${ }^{5}$ Moreover, a patient, while competent, is authorized by statute to designate another person to make treatment decisions for the patient, should he or she become incompetent (a health care agent or proxy), and the patient can make his or her wishes known in advance through a living will., 8

Other important rights were recognized in the 1970s through federal regulations to protect research subjects and state laws and court decisions to protect medical privacy and confidentiality. Patients were also granted access to their medical records, ${ }^{5}$ and the right to basic emergency care was protected. ${ }^{5}$ Proposals for patients'-rights advocates or ombudspersons were not adopted, however, and patients were generally left on their own to exercise their rights. They had recourse to the courts only when their rights had been violated and they had been harmed.

\section{PATIENTS' RIGHTS IN MANAGED CARE}

The key to understanding patients' rights in managed care is to understand managed care's attempt to transform the patient into a consumer. Persons can be considered consumers of health plans if they can choose a plan on the basis of cost, coverage, and quality. ${ }^{9}$ But the choice of a health plan is usually made by employers, and even when it is not, the choice is necessarily much more often based on cost than on coverage or quality. Nor is being a consumer of a health plan the same as being a consumer of health care. In virtually all settings, patients (not consumers) seek the help of physicians when they are sick and vulnerable because of illness or disability. The courts in the 1970s were correct: the doctor-patient relationship is not an arm's-length business transaction; it is a relationship in which trust is essential. Sick people, who are in no position to bargain and who know little about medicine, must be able to trust their physicians to be on their side in dealing with pain, suffering, disease, or disability.

Attempts to transform the physician-patient relationship into a business transaction fundamentally threaten not just physicians as professionals but people as patients. This threat is real, frightening, and intolerable, which is why the new patients'-rights movement aims not simply to preserve the physician-patient relationship in general but also to eliminate the financial conflicts of interest in managed care that are most threatening to the relationship. ${ }^{10}$ Thus, the new patients'-rights movement seeks to shift power not from physicians and hospitals to patients but from managed-care companies, insurance companies, and health care facilities to patients and their physicians.

Some of the recent threats have been highlighted in the media and have already been the subject of federal legislation. Perhaps the most famous, dealt with in detail in a previous article, is "drive-through delivery." Congress and a majority of states responded to limitations on hospital stays after childbirth by mandating coverage for a specific period of hospital care when a physician and a patient agree that it is needed. ${ }^{11}$ The core response to the perception that health plans had gone too far was predictable: an attempt to put the power to make decisions back in the context of a consensual and informed doctor-patient relationship freed from financial conflicts of interest. ${ }^{11}$

In 1997, in response to subsequent proposals to limit "drive-through mastectomy" (modeled on the legislation on drive-through delivery), the AAHP offered "Putting Patients First," also known as the "Nine Commandments." 12 Kassirer has characterized this plan as "a thinly veiled attempt to ward off state and federal legislative actions to curb the abuses of managed care," and it may have been. ${ }^{13}$ Nonetheless, the content of the plan is instructive. None of the nine provisions echo traditional patients' rights. Instead, they all concern areas in which health plans have been widely criticized for restricting care and areas in which medical decisions seem to be made by nonphysicians. For example, the AAHP's proposal would require members (not patients or consumers) to be informed about how the health plan works (e.g., how utilization review is performed, drug formularies are set up, doctors are paid, and treatments are designated as experimental), put decisions about hospitalization for mastectomy in the hands of physicians and their patients, remove any "gag rules" restricting physicians' conversations with their patients about treatment options, describe rights of appeal, and promise "physician involvement" in quality-improvement programs, practice guidelines, and the development of drug formularies.

The AAHP proposal is similar in spirit to the $\mathrm{Na}^{-}$ tional Committee for Quality Assurance's document "Members' Rights and Responsibilities," which focuses on informing members of health plans about their contract with the plan, especially the rules the plan has adopted to make decisions about coverage and the procedures for addressing complaints and resolving disputes. These documents do not qualify as statements of patients' rights in any meaningful way, because they concentrate only on contractual provisions.

The 18 "Principles for Consumer Protection," promoted by Kaiser Permanente, Group Health of Puget Sound, the Health Insurance Plan (HIP), the American Association of Retired Persons, and Families USA in September 1997, seem to go one step further, but it is a small and pathetic step. ${ }^{14}$ The main thrust of the provisions, other than those that duplicate provisions in the other two documents, is to require that all health plans provide certain benefits and services (such as coverage for out-of-area 
emergency care, availability of medical services at all times, and continuity of care through a primary care physician), to disclose specific information (such as the percentage of revenues actually spent on health care [the medical-loss ratio]), and to restrict financial incentives that create conflicts of interest for physicians (including financial incentives to limit care). As the authors concede, these 18 principles are meant not primarily to help patients or customers, but more as a marketing strategy to help health plans compete on an equal basis. ${ }^{14}$

The fact that these contract-centered proposals are almost irrelevant to the typical patient has made comprehensive federal legislation to enforce patients' rights seem both necessary and desirable. Enacting federal legislation is also the only way to protect all patients (not only those who are members of health plans) and to level the playing field for all health plans in the United States. What rights should be included in national legislation?

\section{THE PRESIDENTIAL COMMISSION}

In early 1997, President Clinton took the first step toward a national bill of rights for patients by appointing the Advisory Commission on Consumer Protection and Quality in the Health Care Industry. In November 1997, the commission issued its proposal. Although flawed and incomplete, it provides the basic outline of a national bill of rights for patients. ${ }^{15,16}$ The proposal enumerates four categories of traditional patients' rights (the right to make medical decisions based on full information, the right to confidentiality, the right to emergency care, and the right to be treated with respect), as well as certain contract-based consumer protections (governing contract information, choice of a physician within a plan, and access to an independent appeals mechanism). ${ }^{16}$

The core of patients' rights is the right to receive care from an accountable physician who shares all relevant information with the patient and guarantees the patient the right to make the final decision about treatment. The patient must be able to trust the physician to act honestly and in the patient's best interests. Loyalty to the patient also requires that the physician act as an advocate for the patient when the treatment the physician believes is most appropriate is not covered by the patient's health plan or insurer. Only provisions that honor and reinforce a physician-patient relationship based on trust deserve to be designated patients' rights.

Consumer protection is also important but pales in comparison with the rights of sick people in dealing with physicians and other care givers. Thus, the commission is directly on target to stipulate that any bill of patients' rights include the following: the right to complete information about treatment, the right to emergency care based on what a prudent layperson would regard as an emergency, the right to confidentiality in the handling of medical information, and the right to respectful and nondiscriminatory treatment. ${ }^{16}$ As for the rights of persons enrolled in managed-care plans, it is pretty thin gruel to guarantee access to the contracts they or their employers signed. Nonetheless, the call for an external, independent grievance mechanism to address denials of benefits is welcome. As I pointed out in a previous article, the grievance mechanisms available to patients are woefully inadequate in all health plans. ${ }^{17}$ Much, much more is needed, and the commission is correct in noting that any appeals mechanism must be fair and independent of the health plan. The commission's proposal should have gone further. Patients need access to effective and independent advocates to help them exercise all the rights spelled out in a bill of patients' rights. Advocates can also help patients, together with their physicians, navigate the grievance and appeals procedures with the goal of resolving disputes at the lowest possible level and as quickly and fairly as possible. ${ }^{3,18}$

\section{A BILL OF RIGHTS}

The final shape of a national bill of patients' rights should be the subject of wide-ranging public and congressional debate in 1998. The model adopted, whether geared toward the consumer contract or the physician-patient relationship and whether implemented voluntarily or by federal legislation, will largely determine the ultimate content. And the ultimate content will itself determine whether federal preemption of this area is reasonable. We can call people who buy health insurance consumers and people who join health plans members, but we must recognize that sick people who seek medical care are patients with rights that should be protected. A national bill of patients' rights can and should protect consumers and members of managed-care plans. But its core purpose must be, as President Clinton properly noted, to provide all Americans with basic rights at the time when they mean the most to us - when we are sick and need medical care. ${ }^{1}$

Many of our rights as patients have already been articulated by the courts. Nonetheless, they often remain difficult for patients and providers alike to understand and are especially difficult for sick people to exercise. ${ }^{5,18}$ Thus, enumerating all the essential rights in one document will facilitate an understanding of these rights and make it easier for patients to exercise them in their dealings with physicians, hospitals, and health plans. To this end, I believe a federal bill of patients' rights must include the five core provisions outlined below.

\section{The Right to Treatment Information}

The patient has a right to informed participation in all decisions involving his or her health care, in- 
cluding a clear, concise explanation, in lay terms, of all proposed treatments, the reasonable medical alternatives (whether or not they are covered by the plan), the risks of death and serious complications associated with each alternative (including no treatment), likely problems of recuperation, and the probability of a successful outcome (including the physician's experience with the treatment and its outcomes). The patient has a right to know the diagnosis and prognosis in as much detail as he or she desires, as well as the existence of any research protocols that are relevant to the patient's condition and their availability. A competent patient will not be subjected to any procedures or tests without first providing informed consent. For procedures that entail a risk of death or serious disability, all aspects of informed consent will be explained on a written form requiring the signature of the patient or the person with the authority to make treatment decisions for the patient, if the patient is incompetent. ${ }^{4,5}$

The patient has a right to know the identity, professional status, and clinical experience (including success rates) of all persons responsible for his or her care. The patient has a right to know about all financial arrangements and incentives that might affect his or her care. Any patient who does not speak English has a right to an interpreter. ${ }^{5,10}$

\section{The Right to Privacy and Dignity}

The patient has a right to privacy of both person and information with respect to all medical and nursing personnel, allied health care professionals, health plan and facility staff members, and other patients. All patients must be treated with dignity and without regard to race, religion, sex, sexual orientation, national origin, disability, age, socioeconomic status, or source of payment. The patient has a right to all the information contained in his or her medical record and has a right to examine the record on request, correct mistakes, and receive a copy of it. No one not directly involved in a patient's care or in quality assurance should have access to the patient's medical records without a written authorization by the patient that is dated and limited in time and that specifies the medical information to be disclosed. Further disclosure of medical information without authorization is prohibited. ${ }^{5}$ The patient has a right not to be touched or treated by any particular physician or health care provider, including medical and nursing students.

\section{The Right to Refuse Treatment}

The patient has the right to refuse any drug, test, procedure, or treatment, whether the purpose is therapy, research, or education. A patient may not be discriminated against or denied any benefit by a health plan or health care professional because of the refusal to be touched or treated by a particular pro- vider. A patient has the right to execute a health care proxy or a living will to direct treatment or nontreatment if the patient is no longer capable of making health care decisions, and health care professionals are obligated to honor these advance directives. ${ }^{5,8,16}$

\section{The Right to Emergency Care}

The patient has a right to prompt and competent attention in an emergency. The patient may not be transferred to another facility without his or her consent and, in any event, not before the patient's condition has been stabilized and it has been determined that the transfer is in the patient's best interests because of superior medical care. If the patient does not agree to the transfer, he or she may not be transferred. ${ }^{5}$

\section{The Right to an Advocate}

The patient has the right to the services of an independent patients'-rights advocate with the authority to help the patient assert all the rights specified in the bill of rights. In addition, a patient in a hospital or other health care facility has the right to reasonable visitation, parents have the right to stay with their child, and relatives have the right to stay with patients 24 hours a day. The patient has the right to have a friend or relative present during all consultations, examinations, and procedures, including the induction of anesthesia. ${ }^{5,18}$

Additional provisions of a national patients' bill of rights will involve contract-based consumer protection. How specifically such provisions are spelled out will depend on the extent to which Congress believes health-plan contracts must be regulated. In any event, the following obligations of health plans should be included. No health plan may interfere with or limit communication between the patient and his or her health care provider. Health plans must provide members with a reasonable choice of qualified primary care physicians and reasonable access to specialists. Health plans must disclose to members any and all financial arrangements that might encourage physicians to limit or restrict care, referrals to specialists, or recommendation of noncovered treatments. Health plans must provide payment for emergency services under circumstances that a prudent layperson would consider an emergency. Health plans must provide timely access to an independent appeals mechanism for denial or termination of benefits. ${ }^{16}$

The patient has a right to a copy of the entire contract for his or her insurance or health plan and to competent counseling in selecting a health plan. The patient has a right, regardless of the source of payment, to examine and receive an itemized and detailed explanation of all services rendered. The patient has a right to timely prior notice of termination of eligibility for coverage or denial of a health 
care benefit, with an opportunity to contest the termination or denial in a timely and fair manner before an independent, qualified, and neutral decision maker. $5,10,16$

\section{CONCLUSIONS}

A national bill of patients' rights must cover all Americans. On the other hand, health plans must be held accountable for providing the health care to their members that they hold themselves out as being able to provide. Thus, Congress should also pass legislation that permits members to sue their health plans directly for harm caused by wrongful acts on the part of the plans. ${ }^{19,20}$ Once basic, uniform rights in health care are established, we can return to the equally important task of providing access to health care for all Americans. It seems correct to view universal access to adequate health care as our primary goal. But rights in health care are critical, since without them, citizens may wind up with access to a system that is indifferent to both their suffering and their rights.

\section{REFERENCES}

1. The prepared text of President Clinton's State of the Union message. New York Times. January 28, 1998:A19.

2. Starr P. The social transformation of American medicine. New York Basic Books, 1982:388-93.
3. Annas GJ. The rights of hospital patients. New York: Avon, 1975.

4. Cobbs v. Grant, 8 Cal. 3d 229, 502 P.2d 1 (1972).

5. Annas GJ. The rights of patients. 2nd ed. Carbondale: Southern Illinois University Press, 1989.

6. Roe v. Wade, 410 U.S. 113 (1973).

7. Annas GJ, Glantz LH, Mariner WK. The right of privacy protects the doctor-patient relationship. JAMA 1990;263:858-61.

8. Annas GJ. The health care proxy and the living will. N Engl J Med 1991;324:1210-3

9. Millenson ML. Demanding medical excellence: doctors and accountability in the information age. Chicago: University of Chicago Press, 1997. 10. Rodwin MA. Medicine, money, and morals: physicians' conflicts of in terest. New York: Oxford University Press, 1993.

11. Annas GJ. Women and children first. N Engl J Med 1995;333:1647-51

12. A new look: how managed care is trying to improve its battered image. Modern Healthcare. May 12, 1997:36-46.

13. Kassirer JP. Managing managed care's tarnished image. N Engl J Med 1997;337:338-9.

14. Pear R. Three big health plans urge national standards. New York Times. September 25, 1997:Al.

15. Idem. Panel of experts urges broadening of patient rights. New York Times. October 23, 1997:Al.

16. Advisory Commission on Consumer Protection and Quality in the Health Care Industry. Consumer Bill of Rights and Responsibilities: report to the President of the United States, November 1997.

17. Annas GJ. Patients' rights in managed care - exit, voice, and choice. N Engl J Med 1997;337:210-5.

18. Annas GJ, Healey J. The patient rights advocate: redefining the doctor-patient relationship in the hospital setting. Vanderbilt Law Rev 1974; 27:243-69.

19. Furrow BR. Managed care organizations and patient injury: rethinking liability. Georgia Law Rev 1997;31:419-509.

20. Mariner WK. Liability for managed care decisions: the Employee Retirement Income Security Act (ERISA) and the uneven playing field. Am J Public Health 1996;86:863-9.

(C) 1998, Massachusetts Medical Society.

RECEIVE THE JOURNAL'S TABLE OF CONTENTS EACH WEEK BY E-MAIL

To receive the table of contents of the New England Journal of Medicine by e-mail

every Thursday morning, send an e-mail message to:

\section{listserv@massmed.org}

Leave the subject line blank, and type the following as the body of your message:

subscribe TOC-I

You can also sign up through our website at: http://www.nejm.org 